https://doi.org/10.47370/2078-1024-2021-13-3-140-146

УДК 378.016:004

\title{
Тугуз Ф.А.
}

\section{ЦИФРОВОЕ ОБРАЗОВАНИЕ КАК НОВАЯ ПЕДАГОГИЧЕСКАЯ ПАРАДИГМА}

\author{
Тугуз Фатима Анзауровна, \\ кандидат педагогических наук, дочент кафедры философии, сочиологии \\ и педагогики ФГБОУ ВО «Майкопский государственный технологический \\ университет», Майкоп, Россия, \\ e-mail: fatima-tuguz@mail.ru, \\ тел.: +7.(918) 4247242
}

\section{Аннотация}

Для современного этапа развития общества характерна экспансия цифрового сервиса во все сферы жизни человека, включая образование. Сектору цифровых технологий принадлежит ведущая роль развития цифрового общества. Внедрение цифровых сервисов в образование на всех его уровнях поддерживается государственными инициативами как перспективный ориентир трансформации всего общества с учетом мировых практик. Проблема исследования заключается в изучении механизма цифрового образования как новой педагогической парадигмы.

Цель статьи: обосновать особенности цифрового образования как новой педагогической парадигмы и компонента государственной образовательной политики.

Методы исследования: анализ данных интернет-источников, научных работ, обобщение, систематизация.

Результаты исследования: обоснованы новые возможности образования благодаря использованию цифровых ресурсов; определены основные черты цифрового образования; обозначены перспективы цифрового образования как инновационной модели.

Ключевые выводы: внедрение цифрового образования в вузовскую среду рассматривается в двух контекстах: как необходимое содержание образования и как средство обучения; основными чертами цифрового образования является ориентация на потребительские предпочтения, организация рационального взаимодействия пользователей, алгоритмизированное взаимодействие его пользователей, ориентация на удаленную работу с информационными ресурсами, сетевое взаимодействие и др.; унифицированность для различных потребительских групп; возможность функционирования с помощью разных средств и совместимость с другими приложениями; перспективами цифрового образования выступает построение эргономичной коммуникативной среды учебного заведения, владение всеми субъектами образования цифровыми компетенциями; мотивированность научно-педагогических кадров для работы в новой образовательной среде, обновление учебных дисциплин и др.

Ключевые слова: цифровое образование, цифровые образовательные технологии, парадигма, цифровая парадигма, электронная информационно-образовательная среда, обучающиеся 
Дия циитирования: Тугуз Ф.А. Цифровое образование как новая педагогическая парадигма // Вестник Майкопского государственного технологического университета. 2021. Toм 13, № 3. C. 140-146. https://doi.org/10.47370/2078-1024-2021-13-3-140-146.

Tuguz F.A.

DIGITAL EDUCATION

AS A NEW PEDAGOGICAL PARADIGM

\author{
Tuguz, Fatima Anzaurovna, \\ Candidate of Pedagogy, an associate professor of the Department of Philosophy, \\ Sociology andiPedagogy of FSBEI HE "Maykop State Technological University", \\ Maykop, Russia, \\ e-mail: fatima-tuguz@mail.ru, \\ tel.: +7.(918) 4247242
}

\title{
Annotation
}

The society is characterized by the expansion of digital services into all spheres of human life, including education. The digital technology sector plays a leading role in the development of a digital society. The introduction of digital services into education at all its levels is supported by government initiatives as a promising guideline for the transformation of the entire society, taking into account global practices. The research problem is: what are the mechanisms of digital education as a new pedagogical paradigm?

The purpose of the research is to substantiate the features of digital education as a new pedagogical paradigm and a component of state educational policy.

The research methods are data analysis of Internet sources, scientific works, generalization, systematization.

The research results: new educational opportunities through the use of digital resources have been substantiated; the main features of digital education have been identified; the prospects for digital education as an innovative model have been outlined.

Key findings: the introduction of digital education into a university environment has been considered in two contexts: as a necessary content of education and as a means of teaching; the main features of digital education focus on consumer preferences, organization of rational user interaction, algorithmized interaction of its users, remote work with information resources, network interaction, etc.; infection for various consumer groups; the ability to operate on different means and compatibility with other applications; the prospects for digital education are the construction of an ergonomic communicative environment of an educational institution, the possession of digital competencies by all subjects of education; motivation of scientific and pedagogical personnel to work in a new educational environment, updating academic disciplines, etc.

Keywords: digital education, digital educational technologies, paradigm, digital paradigm, electronic information and educational environment, students

For citation: Tuguz F.A. Digital education as a new pedagogical paradigm // Vestnik Majkopskogo gosudarstvennogo tehnologiceskogo universiteta. 2021. Volume 13, No. 3. P. 140-146. https://doi.org/10.47370/2078-1024-2021-13-3-140-146.

В настоящее время наблюдает- на цифровой сервис всех социальных ся тенденция глобального перехода сфер, в том числе и сферы образования. 
Аргументом в пользу такого утверждения является резкая востребованность цифровых образовательных технологий на всех уровнях образования. Еще в 90-х годах прошлого столетия ряд стран признали создание и дальнейшее совершенствование электронных образовательных ресурсов в числе ведущих направлений внутренней социально-экономической политики, а успешное построение цифрового образовательного пространства - фактом зарождения новой педагогической парадигмы, которая занимает достойное место наряду с компетентностной парадигмой. Поэтому внедрение цифрового сервиса в образовательную практику создает основания говорить о тенденции зарождения новой дидактики, которая позволяет совмещать традиционное обучение с цифровым обучением.

Внедрение цифрового образования в вузовскую среду можно рассматривать в двух контекстах. Первый связан с рассмотрением цифровых образовательных технологий как необходимого содержания образования, а именно наличием в учебных планах любого вуза дисциплин, направленных на формирование универсальных компетенций, предполагающих владение базовыми технологиями управления информацией, умение применять программное обеспечение для хранения, представления, обработки информации и ее передачи. Раскрытию данного контекста посвящены исследования Блинова В.И., Сергеева И.С., Есениной Е.Ю. [1], Ниязовой Ю.М., Гарина А.В., Злыднева М.И. [2], Хайдаровой А.Ш. [3]. Второй аспект подразумевает рассмотрение цифровых образовательных технологий как средства обучения (использование электронной почты, программ для создания презентаций, обучающих онлайн-платформ, создание вузами электронных образовательных сред и пр.). Этот контекст представлен в работах Калининой С.Д. [4], Минченко В.Г., Поддубной Т.Н., Заднепровской Е.Л. [5], Барашкиной Е.В.,
Джум Т.А., Корневой О.А., Дунец Е.Г., Карпенко В.Ю. [6]. Всё это позволяет констатировать активное применение учебными заведениями цифровых систем управления обучением, интерфейс которых включает:

- официальный сайт образовательной организации;

корпоративную коммуникативноинформационную сеть вуза (например, систему электронного документооборота «Электронный университет», автоматизированную систему управления учебным процессом «ВУЗ», «Электронную кафедру»);

- электронно-информационный ресурс научной библиотеки (например, модуль АИБС «МегаПро», ЭБС «Университетская библиотека онлайн»);

- обучающие онлайн-платформы (Moodle, Microsoft Teams, Zoom, Прометей, WebTutor и др.);

- систему сетевого тестирования обучающихся (например, Indigo и др.);

- базы данных электронной информации для использования в учебном процессе на основании заключенных договоров;

- наполнение учебных курсов/дисциплин (учебные материалы по изучаемой дисциплине, домашние задания, задания для контроля знаний студентов) [6].

Таким образом, цифровое образование базируется на цифровом аналоге традиционного обучения (применение в учебной деятельности мультимедиа, онлайн-платформ, веб-ресурсов, облачных сервисов и других EdTech-продуктов), что расширяет в целом возможности образовательной практики в новых условиях цифровизации экономики. Согласно сведениям анализа российского рынка онлайн-образования, в 2020 году в распределении элементов электронной информационно-образовательной среды отечественных вузов преобладали EdTech-продукты, ориентированные на: 44\% - на ресурсы управления 
организацией, $33 \%$ - управления и мониторинга учебного процесса, 20\% - формирования образовательной траектории [6; 7]. В информационно-образовательном пространстве EdTech-продуктов наибольшую популярность в сегменте карьерно ориентированного образования набирают так называемые «буткемпы» - высокоинтенсивные онлайн- и офлайн-программы обучения сотрудников программированию, аналитике и кибербезопасности. Как считает управляющий партнер IT-холдинга TalentTech A. Митюков, «благодаря развитию цифровизации мира и установлению прочной связи образования и карьеры мы сможем стремительно получать новые навыки и даже новые профессии, переквалифицироваться нужное количество раз и постоянно повышать собственную ценность» $[7$, с. 7]. По его мнению, в перспективе через 10-15 лет значимость дипломов, резюме в привычном понимании может быть потеряна, т.к. работодателями будут востребованы необходимые профессиональные навыки. Каждый кандидат будет иметь цифровое портфолио, а также прозрачность в понимании того, какие навыки нужны на рынке труда и кто из соискателей ими обладает. Наиболее доступным и продуктивным способом овладения необходимыми навыками является именно онлайнобразование. Искусственный интеллект позволит осуществить анализ цифрового следа и подсказывать направление создания собственного образовательного трека каждому, что позволит повысить ценность кандидата как профессионала

Обозначим тренды рынка онлайнобразования на основании исследования командой EdMarket.Digital российского рынка образования:

Искусственный интеллект. Разновидностью искусственного интеллекта является персонализация обучения, например, сервис Duolingo, обеспечивающий персонализацию всего образовательного процесса - от предварительного тестирования языковых способностей обучающегося до адаптации контента занятий под индивидуальные способности и динамику языковых навыков.

Микрообучение, основанное на подаче образовательного контента с делением на отдельные смысловые единицы, освоении отдельного микронавыка, независимости от отдельной платформы.

3. Популяризация мобильного обучения (m-learning). По состоянию на 2021 год лидерские позиции по мобильному обучению принадлежат трем группам стран: странам Северной Америки, Европейским государствам и АзиатскоТихоокеанским странам. К 2024 году ожидается увеличение рынка до \$70,1 млрд. (в пределах 17-23\%) (рисунок 1).

Прогноз по росту мирового рынка мобильного обучения

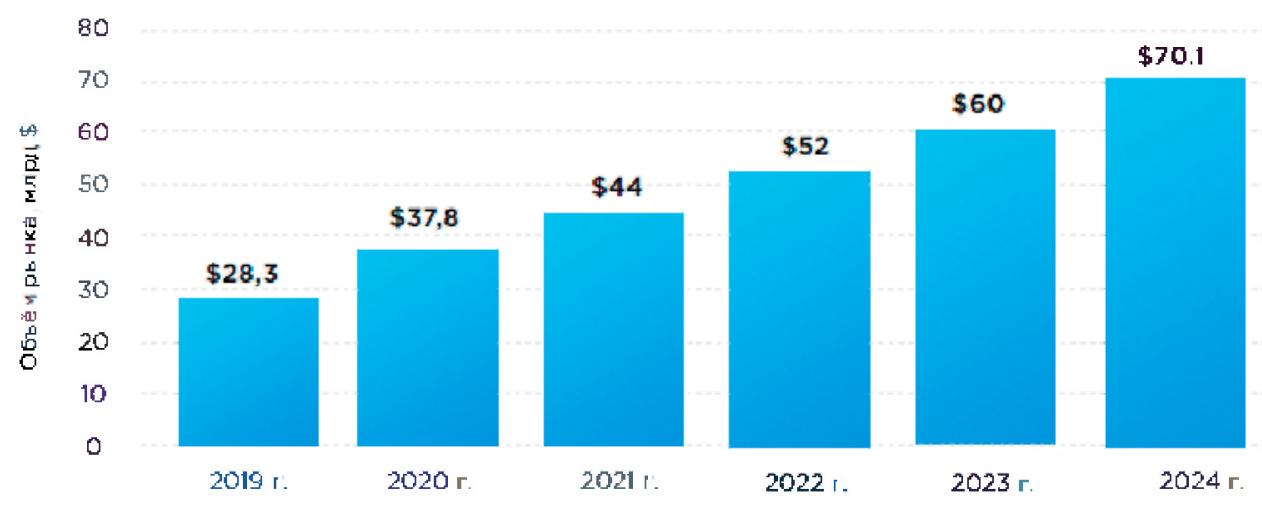

Рис. 1. Прогноз по'росту мирового рынка мобильного обучения [7, с. 27] 
4. Связь онлайн-обучения с практиками talent development («управления талантами»). Сегодня в числе приоритетов профессиональной подготовки рассматривается soft skills сотрудников.

5. Востребованность практик взаимного, так называемого кроссобучения (p2p-learning) с использованием p2p-платформ.

6. Востребованность обучения на основе проектной работы (project-based learning).

7. Доминирование рынка языкового обучения среди направлений EdTech, основанного на сервисах и инструментах для освоения английского онлайн [7, с. 22-32].

При совершенно новом подходе к организации учебного процесса в контексте цифрового образования, тем не менее, устоявшиеся формы организации обучения, методы и средства обучения пока сохраняются. Поэтому традиционная модель практической педагогической деятельности дополняется новым контентом, расширяя в целом возможности учебно-воспитательной деятельности. Анализ исследований по проблеме цифрового образования $[1 ; 2 ; 3 ; 4 ; 5]$ позволил определить основные черты цифрового образования:

- ориентация на потребительские предпочтения с предоставлением широких возможностей для целевого использования - от бизнеса до образования;

- функциональная направленность на организацию рационального взаимодействия пользователей;

- информационно структурировано в направлении алгоритмизированного взаимодействия его пользователей;

- функционально ориентировано на удаленную работу с информационными ресурсами (онлайн-платформами, мобильными приложениями, программами и пр.);

- унифицировано для различных потребительских групп (по возрасту, запросу, профессиональным интересам, любительским предпочтениям);

- может функционировать на разных средствах (стационарных компьютерах, мобильных телефонах, планшетах) и совместимо с другими приложениями;

- предоставляет возможность потребителю использовать сервис в любое время через неограниченный режим доступа;

- использует сетевой принцип работы, в основе которого мульти-кроссдействие участников;

- ориентация на включенность в учебный процесс различных способов восприятия - моторного, зрительного, слухового;

- сетевой доступ в образовательных целях к электронным ресурсам (библиотекам, базам данных, расписанию и пр.), собранным с учетом потребительских предпочтений, из любой точки доступа к сети Интернет;

- возможность проведения онлайнлекций с использованием вебинаров, видеоконференций как дополнительных ресурсов; осуществление записи для многократного использования обучающих видеофрагментов в удаленном режиме.

Следовательно, можно заявить о новых возможностях образования благодаря цифровым ресурсам, следствием чего может выступить поступательная смена педагогической парадигмы, что уже находит отражение в ряде работ современных исследователей. Интересен взгляд С.Д. Калининой, которая высказывает точку зрения о так называемом «параде парадигм в современной педагогике», существующих в образовательном пространстве параллельно (культурологическая, музейная, компетентностная и др.) $[4$, с. 34]. Сегодня данный парад дополнился цифровой парадигмой, что влечет за собой зарождение новой современной 
образовательной среды высшего учебного заведения.

Вполне очевидно, что смена ориентира образования влечет за собой необходимость решения ряда задач, в числе которых построение эргономичной коммуникативной среды учебного заведения; владение всеми субъектами образования цифровыми компетенциями; мотивированность научно-педагогических кадров для работы в новой образовательной среде; разработка локальных актов вуза, регламентирующих правила работы в цифровой среде; обновление учебных дисциплин в аспекте использования цифровых ресурсов и многое другое. Всё это является ближайшим ориентиром модернизации института образования в аспекте построения цифровой архитектоники как инновационной модели учебного заведения.

\section{ЛИТЕРАТУРА:}

1. Блинов В.И., Сергеев И.С., Есенина Е.Ю. Основные идеи дидактической концепции цифрового профессионального образования и обучения. М.: Перо, 2019. 24 с.

2. Ниязова Ю.М., Гарин А.В., Злыднев М.И. Цифровая платформа как информационноэкономическая структура // Компетентность / Competency (Russia). 2021. № 1. C. 31-36.

3. Haidarova A.Sh. Mobile learning: Apps for developing listening comprehension // Молодой ученый. 2020. № 18 (308). С. 448-450.

4. Калинина С.Д. Цифровая педагогика: революционный сдвиг педагогической парадигмы или новое видение современной образовательной среды? // Педагогические науки. 2018. № 5. C. $32-35$.

5. Минченко В.Г, Поддубная Т.Н., Заднепровская Е.Л. Цифровые технологии в образовании: современные вызовы и перспективы // Цифровая экономика и сквозные цифровые технологии: современные вызовы и перспективы экономического, социального и культурного развития / Абашева О.Ю. [и др.]; под ред. Бондаренко И.А., Полетайкина А.Н. Самара: ПНК, 2020. C. $278-292$.

6. The potential of the electronic information-educational environment of a university in professional education: trends and prospects / Barashkina E.V. [at al.] // Propositos y Representaciones. 2021. Vol. 9, № 3.

7. Исследование российского рынка онлайн-образования: [Электронный ресурс]. URL https://innoagency.ru/files/Issledovanie_rynka_rossiyskogo_online_obrazovania_2020.pdf (дата обращения 29.04.2021).

\section{REFERENCES:}

1. Blinov V.I., Sergeev I.S., Yesenina E.Yu. The main ideas of the didactic concept of digital vocational education and training. Moscow: Pero, 2019. 24 p.

2. Niyazova Yu.M., Garin A.V., Zlydnev M.I. Digital platform as an information and economic structure // Competency /. Competency (Russia). 2021. No. 1. P. 31-36.

3. Haidarova A.Sh. Mobile learning: Apps for developing listening comprehension // Young scientist. 2020. No. 18 (308). S. 448-450.

4. Kalinina S.D. Digital Pedagogy: a revolutionary shift in the pedagogical paradigm or a new vision of the modern educational environment // Pedagogical sciences. 2018. No. 5. P. 32-35.

5. Minchenko V.G., Poddubnaya T.N., Zadneprovskaya E.L. Digital technologies in education: modern challenges and prospects // Digital economy and end-to-end digital technologies: modern challenges and prospects for economic, social and cultural development /. Abasheva O.Yu. [et al.]; ed. by Bondarenko I.A., Poletaykina A.N. Samara: PNK, 2020. P. 278-292. 
6. The potential of the electronic information-educational environment of a university in professional education: trends and prospects / Barashkina E.V: [et al.] // Propositos y Representaciones. 2021. Vol. 9. No. 3.

7. Research of the Russian market of online education: [Electronic resource]. URL https:// innoagency.ru/files/Issledovanie_rynka_rossiyskogo_online_obrazovania_2020.pdf(date of access 29/04/2021). 